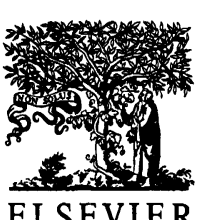

\title{
From the Guest Editor
}

Israel is celebrating its 50th anniversary to its declaration of independence as a state. The State of Israel is still young although the heritage of its Jewish citizens goes back thousands of years. As a young country Israel is still struggling in defining its ideology and ways of living and is affected by both internal issues as well as external processes occurring around the world.

As a young country Israel has grown from half a million in 1947 to approx. 6 million today. There were several large waves of immigration to the country that brought with them diverse cultures, habits and interests. Most recently, during the 1990s, more than a million Jews have arrived from the former Soviet Union to Israel. This immigration contributed to the economic growth and added skilled work force. On the other hand the Ethiopian immigrants, coming from a rural society, needed to adjust to modern life in Israel. They also needed job training in order to join the society as productive citizens. Throughout the years the immigration presented the Israeli society with new social and economic challenges.

Israel is still a country that is threatened by war and is in the process of striving to achieve stability and peace. The process is complicated, long and is affected by fear and hope. As individuals we do not live in a vacuum and as employers and employees we are affected by the security environment in several ways. Naturally, the stress levels and insecurity are reflected in the workplace and interpersonal relationships. This adds to the stress that may exist already due to the nature of one's job. Viewing this, it is somewhat surprising that the area of stress management in the work place is generally neglected, although sporadic efforts are made here and there.

Investors from other countries appear to be reluctant to either invest in projects here or do business when peace in not in sight, thus effecting the growth of the economy and work market. The high taxation due to the defense budget needs is another strain placed on citizens and businesses affecting employment. Resources for the job market; such as workers training, safety measures, and workers rehabilitation depend on the political climate and the budget priorities of the government.

The State of Israel was based on the socialistic ideology and its roots are still effecting politics and economics. The conflict between socialism vs. capitalism and government control vs. open market is strong, but as part of the western world, it appears that the later is getting a hold. All these shifts affect the citizen as a worker, mainly those who work in the basic level of manufacturing and services. These workers see their factories close, benefit conditions worsen, and safety measures lifted to sustain productivity and competition. Israel still has a strong workers union that tries to protect the rights of workers. There are also regulations regarding safety and health and a compensation system at work, however, the existing worker's rehabilitation and job training are insufficient in fulfilling the needs of an injured worker. In his article, Guy Mundlak, Ph.D., will 
try to shed a light on work related health and safety condition in this country.

Israel is a western state with a modern life-style, very success-motivated citizens, with a strong high-tech industry and a progressed medical care. Viewing this, one should be surprised that the ergonomic area is not acknowledged by employers, physicians and the compensation systems to the extent it should be. After spending few years in the USA, working with individuals suffering from cumulative trauma disorder (CTD), I was very surprised and also somewhat frustrated by this. Again, one could claim that the economical climate makes it harder to invest in ergonomic changes and the security situation places priorities elsewhere. Working now in a rehabilitation center I can see that the problem of CTD exists in Israel but is hardly treated. However, therapists are showing interest in this field and are trying to change this situation through caring for their patient's needs. The article by Ratzon et al. and Shenkar et al., touches the area of CTD. The first article examines the multifactorial nature of CTD in workers whose work requires high workload of typing. The second article related to CTD and risk factors in individuals working as dental hygienists. The article by Ben-Shahar et al. reflects a more general research concerning assessment tools used during rehabilitation of injured hands and is relevant for the injured worker.

The relationships between therapists, clinicians, and the work-rehabilitation and compensation institutions are lacking and a multi-disciplinary rehabilitation team geared toward rehabilitating an injured worker hardly exists. The article by Adler et al., on career choices, is an example of data and knowledge clinicians can use. A clinician such as occupational evaluator can develop a cooperation with such an institute to improve the service given to the patients.

One area that is more regulated and studied is the area of occupational exposure to poisonous substances. The Occupational Health and Rehabilitation Institution sent two articles, written by Froom et al., reflecting some of the work done in this area by physicians and neuropsychologists.
This research institution is making efforts to make changes on the legal level and improve the function of physicians working in the occupational medicine area. One rehabilitation area developed and practiced by this institution concerns education for prevention of back injuries amongst workers, an injury that is more acknowledged by physicians and employers.

There are schools and institutions that have programs preparing adolescence with retardation and autism for work, both in sheltered workshops and in the community. Unfortunately, their work is not reflected in this journal volume. Included in this volume were three articles that reflect some aspects of working with developmental difficulties and readiness to work. The article by Hadas-Lidor demonstrated the use of dynamic cognitive model in vocational rehabilitation. The articles by Parush et al. examine the relationship between writing skills and ergonomics issues on one hand and fatigue on the other.

The increasing sophistication of communication technology and the tendency of Israelis to seek knowledge will probably increase both the awareness of the rights, work conditions and work rehabilitation models that exist and are available around the world. It may create different models of work environment, styles, and treatment used in Israel. For example, the article written by Weise et al., view the possible use of the new technology of virtual reality in work-related applications.

The internal characteristics of Israel (i.e. social and religious) and its external conditions (Jewish State in the Middle East) will probably affect the solutions and routes it takes in the area of work conditions and rehabilitation. As Israel will take more steps toward peace and normalcy, priorities and energy will be diverted elsewhere, this will have no doubt a profound effect on social, economics and medical conditions as related to the workplace. Until then, it appears that specific physicians and therapists will have to be the first to 'rock the boat' and make some small scale changes.

I would like to take the opportunity to thank Prof. Karen Jacobs for giving us the opportunity 
to publish such a volume on Israel. This journal volume reflects some of the work and research done in Israel and the high professional level and interests that exist here. During her teaching tour in Israel last summer, she 'boosted' the interest in ergonomics and work rehabilitation and will probably be proud to see the fruits of her efforts amongst therapists.

Asnat Bar-Haim Erez

Israel 